\title{
Ten Years After Arterial Bypass Surgery for Claudication: Venous Bypass is the Primary Procedure for TASC $C$ and D Lesions
}

\author{
Thomas Eugster • Regula Marti • \\ Lorenz Gurke • Peter Stierli
}

Published online: 18 August 2011

(C) Société Internationale de Chirurgie 2011

\begin{abstract}
Background The appropriate role for surgery and endovascular therapy for severe intermittent claudication (IC) remains controversial. We present our results after infrainguinal autogenous bypass for severe IC more than 10 years ago giving a reasoned argument to perform vein bypass as the primary procedure for severe IC.

Methods Our prospectively designed database includes more than 1,000 infrainguinal bypasses following an allautogenous policy. For this review only patients operated on for severe IC at least 10 years ago were included. The primary end points were survival and primary and assistedprimary patency rates.

Results From October 1988 until December 2000, 124 bypasses for IC were performed. Ninety-five patients were male and the mean age was $64.5 \pm 10.8$ years. Survival after 10 years was $50.3 \%$ according to life table analysis. Forty bypasses were to the supragenicular artery, 62 to the infragenicular popliteal artery, and 22 to the tibial artery. Thirty-day mortality was $0.8 \%$ ( 1 patient). The primary patency rate after 10 years was $63.5 \%$ and the assistedprimary patency rate $87.3 \%$.

Conclusion Infrainguinal venous bypass for severe IC has excellent long-term results. Our results are strong arguments against the liberal use of stenting long lesions of the femoropopliteal artery. Venous bypass remains the primary procedure for TASC C and D lesions in claudicants.
\end{abstract}

T. Eugster $(\bowtie) \cdot$ L. Gurke $\cdot$ P. Stierli

Department of Vascular Surgery, University Hospital Basel,

Basel, Switzerland

e-mail: teugster@uhbs.ch

R. Marti

Department of Vascular Surgery, Kantonsspital Aarau,

Aarau, Switzerland

\section{Introduction}

The appropriate role for surgery and endovascular therapy for severe intermittent claudication (IC) remains controversial. In recent years endovascular procedures became increasingly important as therapy for limiting claudication. In 2000, the Trans-Atlantic Inter-Societal Consensus (TASC) introduced a classification scheme for superficial femoral artery (SFA) occlusive disease and proposed guidelines for its management [1]. In 2007, the updated treatment guidelines of the TASC II report were published, which further refined the treatment guidelines based on morphological stratification for aortoiliac and femoropopliteal occlusive disease [2]. For patients with IC and TASC A and B lesions, percutaneous transluminal angioplasty and selective stenting (PTA/S) is the preferred initial therapy. For patients with low operative risk and TASC C and D lesions, greater saphenous vein bypass (GSVB) should be considered [3-5]. Nevertheless, there is an ongoing debate on whether PTA/S or bypass is indicated for superficial femoral artery TASC II C and D disease [6]. With that in mind, the role of GSVB is marginalized, especially for patients with IC. We present our results of infrainguinal autogenous bypass for IC that was performed more than 10 years ago and give a well-supported argument for performing GSVB as the primary procedure for severe IC.

\section{Methods}

Since 1988 all infrainguinal autogenous bypasses performed at our institution are recorded prospectively in a database. For this study we reviewed more than 1,000 bypasses that followed an all-autogenous policy. Harvesting and quality control of the vein are performed as described in a prior publication [7]. 
For this review, patients operated on for severe IC (walking distance $<200 \mathrm{~m}$ ) at least 10 years ago and failed nonoperative management, e.g., walking training, were included. All patients were preoperatively evaluated for cardiac disease according to ACC/AHA guidelines [8]. If considerable cardiac disease was found, the operation was postponed until successful coronary artery revascularization (coronary artery bypass grafting [CABG] or coronary artery stenting) was performed. If this was not possible, the operation was cancelled and the patient was referred to the best medical treatment possible.

Follow-up was every 3 months during first year and than annually. If a patient missed follow-up, he was invited again and a phone call to his physician was made. Therefore, there was a low dropout rate during follow-up. All patients received oral anticoagulation with Coumadin ${ }^{\circledR}$ (Bristol-Myers Squibb) postoperatively. Six months after the procedure, the treatment was changed to aspirin alone in patients with supragenicular bypasses and control duplex without signs of stenosis.

The primary end points were survival and primary and assisted-primary patency rates. Secondary patency is not appropriate since occluded bypasses were not reopened but redone. Results were reported according to the recommended SVS reporting standards [9].

\section{Results}

From October 1988 through December 2000, 124 infrainguinal venous bypasses were performed for IC in 110 patients. Patient demographics are listed in Table 1. Mean age was $63.7 \pm 12.1$ years. Ninety-five patients were male $(77 \%)$. Surgery was performed for severely limiting claudication (Fontaine stadium IIB) in all patients. The site of the distal anastomosis in 40 (32\%) cases was to the supragenicular popliteal artery, in $62(50 \%)$ the infragenicular artery, and in $22(18 \%)$ the tibial artery. In 107 patients (86\%), one piece of greater saphenous vein could be used, and in 17 patients (14\%), spliced veins, including arm veins, were necessary following our all-autogenous policy. Fifteen patients (12\%) needed CABG during follow-up.

Mean follow-up time was $76.6 \pm 58.3$ months (Table 2). One patient died on postoperative day 5 due to myocardial infarction yielding an in-hospital and 30-day mortality of $0.8 \%$. After 10 years of follow-up, the life-table survival rate was $50.3 \%(\mathrm{SE} \pm 5.42 \%)$. Primary patency rate after 10 years was $63.5 \%(\mathrm{SE} \pm 7.50 \%)$ and assisted-primary patency rate was $87.3 \%$ (SE $\pm 5.19 \%)$. Both patency and survival rate showed a continuous decline without a sharp drop, as seen in Figs. 1 and 2. Patency rates of spliced and nonspliced vein bypasses were not different.
Table 1 Patient demographics and characteristics $(n=124)$

\begin{tabular}{lll}
\hline & $n$ & $\%$ \\
\hline Gender (female/male) & $29 / 95$ & $23 / 77$ \\
Side (left/right) & $64 / 60$ & $52 / 48$ \\
Age (years) & $64.5( \pm 10.8$, range $=38-86)$ & \\
Diabetes & 30 & 24 \\
Tobacco use & 52 & 42 \\
Hypertension & 34 & 27 \\
Site of distal anastomosis & & \\
$\quad$ Supragenicular & 40 & 32 \\
Infragenicular & 62 & 50 \\
$\quad$ Tibial & 22 & 18 \\
Vein conduit & & 86 \\
One piece of GSV & 107 & 14 \\
$\quad$ Spliced and arm veins & 17 & 11 \\
Bypass on both legs & 14 & 12 \\
CABG during follow-up & 15 & \\
\hline
\end{tabular}

$G S V$ Greater saphenous vein, $C A B G$ coronary artery bypass grafting

Table 2 Results of infrainguinal venous bypass $(n=124)$

\begin{tabular}{lll}
\hline Follow-up mean (months) & $76.6 \pm 58.3$ & \\
Mortality (30 days) & $1(0.8 \%)$ & \\
$\begin{array}{l}\text { Survival rate after } \\
10 \text { years (life-table) }\end{array}$ & $50.3 \%$ & SE $5.42 \%$ \\
$\begin{array}{l}\text { Occlusion rate (total) } \\
\text { Primary patency after } \\
\quad 10 \text { years (life-table) }\end{array}$ & $13(9 \%)$ & \\
$\begin{array}{l}\text { Primary assisted patency after } \\
10 \text { years (life-table) }\end{array}$ & $87.5 \%$ & SE $7.50 \%$ \\
\hline
\end{tabular}

$S E$ standard error

\section{Discussion}

With the recent explosion in technological advances, accepted consensus no longer seems valid. TASC II C lesions and, increasingly, TASC II D lesions are treated with primary endovascular therapy [10-12]. Primary patencies after these interventions range from 54 to $63 \%$ after 1 year [10-12] and 22\% after 4 years [10]. Today so-called full-metal-jacket stenting of the superficial femoral artery is being done with promising results [13]. Shah et al. [13] reported a median primary patency of 55\% after 6 months. They report a limb salvage rate of $85 \%$ while $65 \%$ of the patients were claudicants. This study shows how patients with IC present with critical ischemia following failure of their endovascular operation.

The RESILIENT randomized trial, a multicenter randomized study, compared primary stenting to balloon angioplasty, with provisional stent implantation for moderate-length 
Fig. 1 Life-table analysis of 124 patients operated on for claudication. Numbers give bypasses at risk

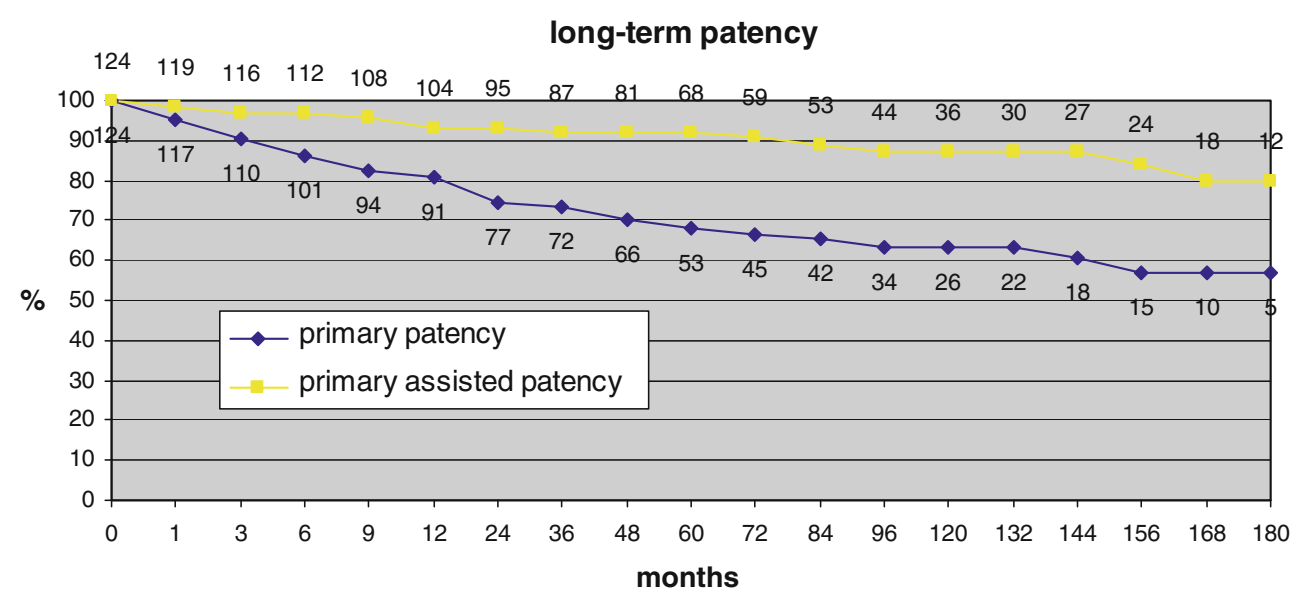

Fig. 2 Life-table analysis for long-term survival of 124 patients. Numbers give bypasses at risk

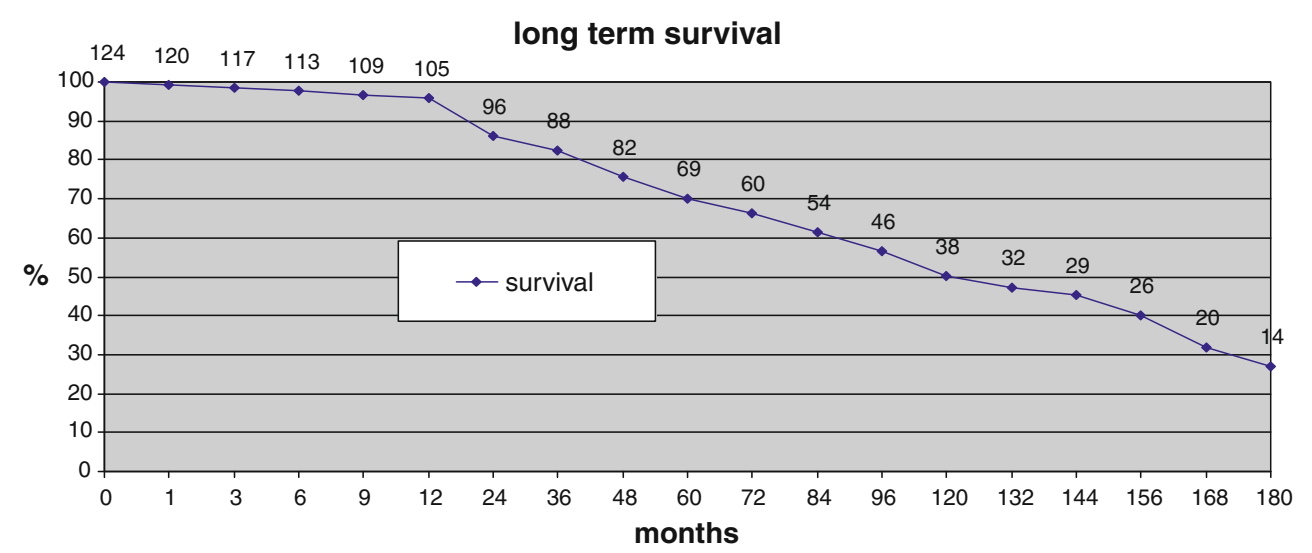

lesions and for patients with intermittent claudication [14]. Primary patency at 12 months was $81.3 \%$ for the stent group versus $36.7 \%$ for the PTA group. The authors concluded that longer lesions of the superficial femoral artery are better treated with PTA/S than with PTA alone.

Ferreira et al. [15] report a primary patency rate of $69 \%$ after 4.8 years and an assisted-patency rate of $90 \%$ after 5 years in stented SFAs. The length of the lesions ranged from 3 to $53 \mathrm{~cm}($ mean $=19 \mathrm{~cm})$. Most of the patients (61\%) had TASC D lesions. Most of the patients $(97.8 \%)$ had limiting claudication. These good results are dampened by the fact that three patients had to undergo amputation following failed reopening of occluded stents.

Endovascular treatment of the infrapopliteal arteries is discussed by Krankenberg et al. [16]. They present 78 patients with intermittent claudication and lesions of the infrapopliteal arteries. After 12 months the primary patency rate was $66.3 \%$.

The difficult anatomic situations at the distal superficial femoral artery and the popliteal artery are responsible for the limitations of PTA and stenting. Laird [17] demonstrates the difficulties specific to the femoropopliteal segment due to repetitive deformation in multiple directions by leg movement. This leads to stent fracture, which can be associated with a higher risk of restenosis. Scheinert et al. [18] investigated the incidence of femoral nitinol stent fractures by radiographic screening in 93 patients at a mean follow-up of 10.7 months after stent implantation. They found stent fractures in $45(37.2 \%)$ of 121 treated legs. The primary patency rate at 12 months was significantly lower for patients with stent fractures $(41.1 \%$ vs. $84.3 \%, P<0.0001)$.

In-stent stenosis and stent occlusion are not benign. In the study by Sabeti et al. [11], one third of the patients had deterioration of their tibial arterial runoff. Recent results of clinical outcomes and implications of failed infrainguinal endovascular stents are presented by Gur et al. [19]. They found that TASC C and D lesions are more likely to fail with occlusion, lose runoff vessels, and alter the site of subsequent open operation than their TASC A and B counterparts. They stated that although these complications are infrequent, they may negatively impact later attempts at revascularization [19].

Both the superficial femoral artery and the supragenicular popliteal artery are commonly involved in TASC C and D lesions. In our patients we had to perform $22(18 \%)$ bypasses to tibial arteries. Our long-time results are 
supported by several published studies [20-22]. Therefore, we believe that tibial bypasses can be justified in selected well-informed patients with severe IC after conservative treatment failed.

Our study has several limitations. Although prospectively acquired, data have been retrospectively analyzed. Due to the nature of cardiovascular disease, every longtime follow-up study has to deal with a considerable loss of patients, as shown at Fig. 2. After 10 years half of the patients had died, mostly from cardiac problems. Furthermore, it is not possible to compare bypasses and endovascular procedures since endovascular treatment was not available at the time the bypasses were performed. Only a prospective randomized study could compare the two procedures. Due to the nature of the interventions, randomization of patients would be very difficult to do. Furthermore, the benefits of bypass are greater as time passes. Therefore, conclusive results would be available only after long-time follow-up.

In conclusion, the use of stenting in TASC C and D disease may become a valuable alternative to bypass surgery with future improvement of the endovascular armamentarium. Until now, the published results do not justify treating long femoropopliteal lesions by endovascular means instead of surgical bypass.

\section{References}

1. Dormandy J, Rutherford R (2000) Management of peripheral artery disease (PAD): Trans Atlantic Inter-Society Consensus (TASC). J Vasc Surg 31:S1-S296

2. Norgren L, Hiat WR, Dormandy JA, Nehler MR, Harris KA, Fowkes FGR, on behalf of the TASC II Working Group (2007) Inter-society consensus for the management of peripheral arterial disease (TASC II). Eur J Vasc Endovasc Surg 33:S1-S75

3. Nolan B, Finlayson S, Tosteson A, Powell R, Cronenwett J (2007) The treatment of disabling intermittent claudication in patients with superficial femoral artery occlusive disease-decision analysis. J Vasc Surg 45:1179-1184

4. Dearing DD, Patel KR, Compoginis JM, Kamel MA, Weaver FA, Katz SG (2009) Primary stenting of the superficial femoral and popliteal artery. J Vasc Surg 50:542-547

5. Menard MT, Belkin M (2007) Infrapopliteal intervention for the treatment of the claudicant. Semin Vasc Surg 20:42-53

6. Dosluoglu HH, Cherr GS, Lall P, Harris LM, Dryjski ML (2008) Stenting vs above knee polytetrafluoroethylene bypass for TransAtlantic Inter-Society Consensus-II C and D superficial femoral artery disease. J Vasc Surg 48:1166-1174

7. Eugster T, Gurke L, Obeid T, Stierli P (2002) Infrainguinal arterial reconstruction: female gender as risk factor for outcome. Eur J Vasc Endovasc Surg 24:245-248
8. ACC/AHA Task Force Report (1996) Special report: guidelines for perioperative cardiovascular evaluation for noncardiac surgery. Report of the American College of Cardiology/American Heart Association task force on practice guidelines (Committee on Perioperative Cardiovascular Evaluation for Noncardiac Surgery). J Cardiothorac Vasc Anaesth 10:540-552

9. Rutherford RB, Baker D, Ernst C, Johnston KW, Porter JM, Ahn $S$ et al (1997) Recommended standards for reports dealing with lower extremity ischemia: revised version. J Vasc Surg 26: $517-538$

10. Cheng SWK, Ting AWC, Ho P (2003) Angioplasty and primary stenting of high-grade, long segment superficial femoral artery disease: Is it worthwhile? Ann Vasc Surg 17:430-437

11. Sabeti S, Mlekusch W, Amighi j, Minar E, Schillinger M (2005) Primary patency of long-segment self-expanding nitinol stents in the femoro-popliteal arteries. J Endovasc Ther 12:6-12

12. Ihnat DM, Duong ST, Taylor ZC, Leon LR, Mills JL, Goshima KR et al (2008) Contemporary outcome after superficial femoral artery angioplasty and stenting: the influence of TASC classification and runoff score. J Vasc Surg 47:967-974

13. Shah PS, Hingorani A, Ascher E, Shiferson A, Gopal K, Jung D et al (2011) Full metal jacket stenting of the superficial femoral artery: a retrospective review. Ann Vasc Surg 25:127-131

14. Laird JR, Katzen BT, Scheiner D, Lammer J, Carpenter J, Buchbinder $M$ et al (2010) Nitinol stent implantation versus balloon angioplasty for lesions in the superficial femoral artery and proximal popliteal artery: twelve-month results from the RESILIENT randomized trial. Circ Cardiovasc Interv 3:267-276

15. Ferreira M, Lanziotti L, Monteiro M, Abuhadba G, Capotorto LF et al (2007) Superficial femoral artery recanalization with selfexpanding nitinol stents: long-term follow-up results. Eur J Vasc Endovasc Surg 34:702-708

16. Krankenberg H, Sorge I, Zeller T, Tübler T (2005) Percutaneous transluminal angioplasty of infrapopliteal arteries in patients with intermittent claudication: acute and one-year results. Catheter Cardiovasc Interv 64:12-17

17. Laird JR (2006) Limitations of percutaneous transluminal angioplasty and stenting for the treatment of disease of the superficial femoral and popliteal arteries. J Endovasc Ther 13(Suppl 2):II30II 40

18. Scheinert D, Scheinert S, Sax J, Piorkowski C, Bräunlich S, Ulrich $M$ et al (2005) Prevalence and clinical impact of stent fractures after femoropopliteal stenting. J Am Coll Cardiol 45:312-315

19. Gur I, Lee W, Akopian G, Rowe VL, Weaver FA et al (2001) Clinical outcomes and implications of failed infrainguinal endovascular stents. J Vasc Surg 53:658-666

20. Conte MS, Belkin M, Donaldson MC, Baum P, Mannick JA, Whittemore AD (1995) Femorotibial bypass for claudication: do results justify an aggressive approach? J Vasc Surg 21:873-880

21. Byrne J, Darling RC, Chang BB, Paty PS, Kreienberg PB et al (1999) Vascular Surgical Society of Great Britain and Ireland: review of 94 tibial bypasses for intermittent claudication. Br J Surg 86:706-707

22. Curi MA, Skelly Cl, Woo DH, Desai TR, Katz D, McKinsey JF et al (2002) Long-term results of infrageniculate bypass grafting using all-autogenous composite vein. Ann Vasc Surg 16:618-623 